\title{
Analysis Using Various Approaches for Residual Life Estimation of Power Transformers
}

\author{
Deepak Kanumuri, Veena Sharma, and O. P. Rahi
}

\author{
Electrical Engineering Department, NIT Hamirpur (H.P), India
}

\begin{abstract}
Transformers are the most important links between generation, transmission and distribution of a power system. Their failure can cause huge revenue loss to utilities as there is non-availability of power for long hours. Several factors like high load, overheating and short circuits influence the aging of the insulating system present in transformer. Many diagnostic tests are carried out and remedial actions are taken for ensuring non-interrupted, trouble free power supply to customers. End of useful life of a power transformer is determined by the remaining life of paper insulation in the transformer. The aging in the paper insulation is determined by mechanical strength or tensile strength of the solid insulation and is measured in terms of its Degree of Polymerization (DP). The traditional method for determining DP is called the direct method and it requires actual paper samples therefore making it costly and intrusive. Recently an indirect method is used, which estimates the DP value from the furan compounds dissolved in the oil and this is a non-intrusive process. This paper presents analysis of various indirect methods used in remaining life estimation and also comparative studies have been made among the mathematical equations developed by various researchers correlating 2 - furaldehyde and DP with respect to ageing process.
\end{abstract}

Keywords: Residual life assessment, Furan concentrations, Degree of polymerization, Correlation between DP and 2-FAL.

\section{Introduction}

Proper operation of transformer is critical to ensure transmission and distribution of electricity in a power system. Optimal use of these transformers ensures economic and reliable power supply. Due to deregulation, the electrical utilities are under pressure in reducing the generation cost of electricity and are left with an option of using power apparatus near to their rated values. This rated and sometimes short overloading of transformers leads to health deteriorations, electrical and thermal stresses. So, for maintaining and checking the health of transformer its essential to go for condition monitoring of transformers. The life of transformer is generally estimated to be 25 to 30 years as per IEEE loading guide lines [1]. But there are many transformers in service for more than 30 years in electricity board because of extensive condition monitoring and residual life assessment technique applications. These techniques prevent unpredicted outages and hence saving revenues in a power system.

Insulation system of most transformers is composed of dielectric oil and solid paper insulation. State of this insulation describes the status of each unit as many variables may influence aging process in a transformer. Factors influencing ageing of the insulation system in transformer are: overheating, long periods of operation at high load, oxidation, moisture, high currents etc. Moisture and temperature of paper and oil are most important causes in ageing of the insulating system and oxidation accelerates the degradation of insulation paper. Dielectric oil present in transformers decomposes to hydrogen and low molecular weight gases such as acetylene, ethane, ethylene, methane etc and these gases are identified by dissolved gas analysis. The percentage of these gases varies from one transformer to another based on different conditions which occur inside a transformer or during its operation. On other side, when the solid insulation (i.e. Kraft paper) of these transformers decomposes, different products such as $\mathrm{CO}$, $\mathrm{CO}_{2}$, water and small amounts of furan compounds appear in oil. This knowledge of insulation decomposition allows to evaluate the status of insulation and health deterioration through

Received: December $19^{\text {th }}, 2018$. Accepted: June $23^{\text {rd }}, 2019$

DOI: 10.15676/ijeei.2019.11.2.11 
monitoring of various parameters. Parameters like acidity, dielectric strength, water content, gas content, loss factor and concentration of furans in transformer oil are vital indicators to determine the condition of a transformer.

In this paper, a brief review of mathematical models will be presented which defines the accuracy of the equations describing correlation between 2-furaldehyde and DP. Comparative studies are done for these equations by considering the data of these transformer and their oil test reports are also compared with standard oil properties of in-service oil.

The standard properties of oil considered in this paper are IEC 60156-95 for breakdown voltage whose limits for in service oil are $30(<72.5 \mathrm{KV}) ; 40(>72.5 \mathrm{KV})$ and for new oil it is $40(<72.5 \mathrm{KV}) ; 50(>72.5 \mathrm{KV})$, IEC $60814-1997$ for water content whose limits for in service oil are 20(>170KV); $40(<170 \mathrm{KV})$ and for new oil 10(>170KV); $15(<170 \mathrm{KV})$, IEC 62021-2 for total acidity whose limits for in service oil are 0.3 and for new oil it is 0.03, IEC 60247:2004 for tan delta at $90^{\circ} \mathrm{C}$ whose limits are $0.2(>170 \mathrm{KV}) ; 0.1(<170 \mathrm{KV})$ for in service oil and for new oil it is $0.015(>170 \mathrm{KV}) ; 0.01(<170 \mathrm{KV})$, IEC $60247: 2004$ for specific resistivity at $90^{\circ} \mathrm{C}$ whose limits are 1 at $27^{\circ} \mathrm{C} ; 0.1$ at $90^{\circ} \mathrm{C}$ for in service oil and for new oil it is 6 at $90^{\circ} \mathrm{C}$, ISO 2719 for flash point for in service oil it is $125(\mathrm{~min})$ and for new oil it is $140(\mathrm{~min})$, ASTM D 7483 for viscosity and for new oil its value should be 27 at $27^{\circ} \mathrm{C}$, ISO 12185 for density whose limits for in service oil and new oil is 0.895 at $29.5^{\circ} \mathrm{C}$,ASTM D 971-91 for interfacial tension whose limits for in service oil is $15 \mathrm{mN} / \mathrm{m}$ at $90^{\circ} \mathrm{C}$ and for new oil it is $35 \mathrm{mN} / \mathrm{m}$ at $90^{\circ} \mathrm{C}$.

All these parameters are compared with in-service oil limits. Similarly, furan analysis data is also used in all these mathematical models given by different researchers and remaining life is calculated through the estimated degree of polymerization obtained from these models.

Transformer Specifications and Reports

Table 1. Transformer specifications [2]

\begin{tabular}{|c|l|c|c|c|c|c|c|}
\hline S. no & Parameter & $\operatorname{Tr} 1$ & $\operatorname{Tr} 2$ & $\operatorname{Tr} 3$ & $\operatorname{Tr} 4$ & $\operatorname{Tr} 5$ & $\operatorname{Tr} 6$ \\
\hline 1. & $\begin{array}{l}\text { Voltage class } \\
(\mathrm{KV})\end{array}$ & $132 / 66$ & $132 / 66$ & $132 / 11$ & $132 / 11$ & $132 / 11$ & $132 / 66$ \\
\hline 2. & $\begin{array}{l}\text { Capacity } \\
\text { (MVA) }\end{array}$ & $40 / 50$ & 12.5 & 20 & 12.5 & 20 & 20 \\
\hline 3. & $\begin{array}{l}\text { Age } \\
\text { (years) }\end{array}$ & 45 & 44 & 46 & 45 & 45 & 46 \\
\hline 4. & Year of make & 1974 & 1975 & 1973 & 1974 & 1974 & 1973 \\
\hline
\end{tabular}

All these transformers consist of naphtha-based oil and cooling system used is ONAN/ONAF.

Table 2. Oil Reports of various parameters in transformers [2]

\begin{tabular}{|c|l|c|c|c|c|c|c|}
\hline S. no & \multicolumn{1}{|c|}{ Parameter } & $\operatorname{Tr} 1$ & $\operatorname{Tr} 2$ & $\operatorname{Tr} 3$ & $\operatorname{Tr} 4$ & $\operatorname{Tr} 5$ & $\operatorname{Tr} 6$ \\
\hline 1. & $\begin{array}{l}\text { Breakdown } \\
\text { Voltage }\end{array}$ & 51.7 & 24.7 & 12.5 & 72.6 & 44.3 & 58.9 \\
\hline 2. & Water Content & 26.4 & 37.6 & 73.2 & 13.9 & 23.1 & 18 \\
\hline 3. & Total Acidity & 0.02367 & 0.04327 & 0.04327 & 0.0154 & 0.01056 & 0.00921 \\
\hline 4. & Tan Delta at $90^{\circ} \mathrm{C}$ & 0.059012 & 0.044558 & 0.09866 & 0.041666 & 0.037315 & 0.024045 \\
\hline 5. & $\begin{array}{l}\text { Specific } \\
\text { Resistivity at } \\
90^{\circ} \mathrm{C}\end{array}$ & 0.3 & 0.5 & 0.255 & 0.587 & 0.6 & 0.988 \\
\hline 6. & Flash Point & 149 & 147 & 149 & 145 & 151 & 151 \\
\hline 7. & Viscosity & $\mathrm{NT}$ & $\mathrm{NT}$ & $\mathrm{NT}$ & $\mathrm{NT}$ & $\mathrm{NT}$ & $\mathrm{NT}$ \\
\hline 8. & $\begin{array}{l}\text { Interfacial } \\
\text { Tension }\end{array}$ & 11.70 & 08.77 & 10.37 & 18.98 & 12.19 & 12.48 \\
\hline
\end{tabular}


Table 3. DGA test reports of transformers [2]

\begin{tabular}{|c|l|c|c|c|c|c|c|c|}
\hline S.no & DGA parameters & $\operatorname{Tr} 1$ & $\operatorname{Tr} 2$ & $\operatorname{Tr} 3$ & $\operatorname{Tr} 4$ & $\operatorname{Tr} 5$ & $\operatorname{Tr} 6$ & Max \\
\hline 1. & $\mathrm{H}_{2}$ & 72 & 48 & 3712 & Nil & 313 & 82 & 100 \\
\hline 2. & $\mathrm{CO}_{2}$ & 1962 & 1340 & 2387 & 2367 & 2924 & 3483 & 2500 \\
\hline 3. & $\mathrm{CO}$ & 265 & 75 & 39 & 185 & 275 & 335 & 350 \\
\hline 4. & $\mathrm{C}_{2} \mathrm{H}_{4}$ & 6 & 2 & 4 & 14 & 16 & 98 & 50 \\
\hline 5. & $\mathrm{C}_{2} \mathrm{H}_{6}$ & 18 & 28 & 18 & 27 & 28 & 36 & 65 \\
\hline 6. & $\mathrm{CH}_{4}$ & 7 & 3 & 10 & 10 & 13 & 9 & 120 \\
\hline 7. & $\mathrm{C}_{2} \mathrm{H}_{2}$ & $\mathrm{Nil}$ & $\mathrm{Nil}$ & $\mathrm{Nil}$ & $\mathrm{Nil}$ & $\mathrm{Nil}$ & $\mathrm{N}$ & 1 \\
\hline
\end{tabular}

Table 4. Furan test reports of transformers [2]

\begin{tabular}{|c|c|c|c|c|c|c|c|}
\hline S.no & Name & $\operatorname{Tr} 1$ & $\operatorname{Tr} 2$ & $\operatorname{Tr} 3$ & $\operatorname{Tr} 4$ & $\operatorname{Tr} 5$ & $\operatorname{Tr} 6$ \\
\hline 1. & $5 \mathrm{H} 2 \mathrm{~F}$ & 1.126 & 0.042 & 0.068 & 0.012 & 0.000 & 0.027 \\
\hline 2. & $2 \mathrm{FAL}$ & 0.045 & 0.0976 & 1.122 & 0.416 & 0.492 & 0.447 \\
\hline 3. & $2 \mathrm{ACF}$ & 0.114 & 0.065 & 0.092 & 0.057 & 0.000 & 0.000 \\
\hline 4. & $5 \mathrm{M} 2 \mathrm{~F}$ & 0.000 & 0.069 & 0.066 & 0.062 & 0.061 & 0.056 \\
\hline & total & 1.285 & 1.153 & 1.348 & 0.547 & 0.553 & 0.530 \\
\hline
\end{tabular}

Based on all the test reports of oil properties, DGA, furan tests, following conclusions can be drawn

In Transformer 1, oil reports show low interfacial tension which indicates presence of polar contaminants and may also indicate poor compatibility of oil with various materials used in transformer. All gases in DGA report are within limits. Action to be taken is the replacement or refurbishment of oil. Transformer life is above 42 years and 2-FAL concentration is very low that is $0.045 \mathrm{ppm}$, reason is oil was replaced in 2008 so the furan concentration is remarkably less.

In Transformer 2, oil reports show low breakdown voltage which confirms the presence of contaminants like water or moisture. It also shows high-water content by which deterioration of paper is accelerated, low interfacial tension indicates the presence of polar contaminants in dielectric oil.

In Transformer 3, dark reddish-brown colour of oil validates ageing and chemical contaminants. Low interfacial tension and BDV indicates high moisture level present in oil. High 
concentration of hydrogen in DGA reports show the occurrence of partial discharge and $\mathrm{CO}_{2}$ indicates cellulose decomposition. So, immediate action to be taken is replacement of oil. From furan concentration, 2FAL is $1.122 \mathrm{ppm}$, it is clear from furan analysis that the overheating and cellulosic decomposition has taken place.

In Transformer 4, dark reddish colour indicates presence of sediments. Apart from this, oil is healthy and due to previous oil replacements, 2FAL concentration is less. Hence, this transformer could work for another 10 years.

In Transformer 5, high water content, low interfacial tension and high concentration of hydrogen indicates presence of low energy discharges and polar contaminants. Low energy discharges occur due to arcing between ruptured connection of windings, breakdown of oil, and discharges between clamping parts, bushings and tanks, high voltage and ground.

In Transformer 6, low interfacial tension and high concentration of $\mathrm{CO}_{2}, \mathrm{C}_{2} \mathrm{H}_{2}$ and ethylene reflects occurrence of thermal fault. Hence transformer must be checked for arcing between connections of windings, breakdown of oil, discharges between bushings and tanks, clamping parts, high voltage and ground.

\section{Furan Formation and Correlation Between 2-FAL and DP}

Solid insulation in transformers contains cellulose and when subjected to $100^{\circ} \mathrm{C}$ and above due to various reasons, will generate by-products of degradation and some of them are soluble in oil. These by-products are a result of ageing and get dissolved in oil, therefore, this oil can be analysed for the presence furan concentration. These can be easily sampled and can be used as ageing indicators. Recent studies suggest that furan compounds which are generated due to electrical discharges affect the cellulose, but in very less amount. Due to thermal stress or thermal ageing, furanic compounds of huge quantities could be generated as these cellulosic materials of solid insulation are subjected to a very high temperature (i.e. $120^{\circ} \mathrm{C} \mathrm{\&} \mathrm{above).} \mathrm{The} \mathrm{rate} \mathrm{of}$ formation of these furanic compounds can be a function of various other factors such as water content and oxygen concentration. Measurement of furanic compounds are done in ug/L. While there are many furanic compounds, most of them are unstable in the eluent. There are 5 furanic compounds that are used commonly for all types of diagnostic processes and are given below as [3]:

1) 2-Furaldehyde (2-FAL)

2) 5-Methyl-2-Furaldehyde (5M2F)

3) 5-Hydroxylmethyl-2-Furaldehyde $(5 \mathrm{H} 2 \mathrm{~F})$

4) 2-Acetyl Furan (2ACF)

5) 2-Furfuryl Alcohol (2FOL)

Table 5. Causes for generation of furanic compounds [4]

\begin{tabular}{|l|l|l|}
\hline S.no & Compound & Observed cause \\
\hline 1. & 2-Furaldehyde & Overheating and normal aging \\
\hline 2. & 5-Methyl-2-Furaldehyde & High temperatures \\
\hline 3. & 2-Acetyl Furan & Rare, no definite cause \\
\hline 4. & 5-Hydroxylmethyl-2-Furaldehyde & Oxidation \\
\hline 5. & 2-Furfuryl Alcohol & High moisture \\
\hline
\end{tabular}

Furanic compounds stability draws more interest because it is helpful in drawing conclusions from the analysis done. These unstable compounds will lead to inaccurate conclusion by the engineer. Among the above mentioned furanic compounds, some are established due to ageing and due to different conditions, they are very unstable. Therefore, all of them are not useful. From laboratory tests conducted by different researchers the studies have shown, that 2furaldehyde (2FAL) also known as 2 furfural of cellulose ageing in insulation system is most stable by-product for years. So, it is widely used for predicting the paper DP value. 
Table 6. State of transformer insulation based on 2-FAL concentration [4]

\begin{tabular}{|c|c|c|}
\hline S.no & $\begin{array}{c}\text { Condition of } \\
\text { insulation }\end{array}$ & $\begin{array}{c}\text { Concentration }(\mathrm{ppm}) \text { of } \\
\text { 2-FAL }\end{array}$ \\
\hline 1. & Good & 2FAL $<0.5$ \\
\hline 2. & Acceptable & $0.5 \leq 2 \mathrm{FAL} \leq 1$ \\
\hline 3. & Need caution & $1.1 \leq 2 \mathrm{FAL} \leq 1.5$ \\
\hline 4. & Poor & $1.6 \leq 2 \mathrm{FAL} \leq 2$ \\
\hline 5. & Very poor & 2FAL $\geq 2.1$ \\
\hline
\end{tabular}

Correlation between 2-FAL and DP of paper insulation

Recent studies have found that by analysing oil for furanic compound concentration those are formed during ageing, indirect tests can be carried out on them. During the ageing process furanic compounds transfer from paper to oil and by analysing this oil, DP value can be estimated. Furanic compounds that are measured from an oil sample are relatively simple, but the interpretation is complex. As mentioned before, in ageing process more than one mechanism are involved. At low temperature, carbon-oxide gases and moisture are more dominant products at intermediate temperatures these compounds are dominant and are highly unstable at high temperatures. Several researchers have investigated ageing of paper and have attempted to correlate furans to DP value. All these studies are based on data obtained from different specimen from laboratory tests by taking transformers out of service for repairs. Arrhenius model for loss of life is constructed on the theory that the only condition for ageing is temperature and it depends on hottest spot in a transformer. Arrhenius equation is given below [5]

$$
L o L \%=100 * \Delta t * 10^{-\left[A+\frac{B}{\Theta+273}\right]}
$$

where,

LoL\%-loss of life

A, B - ANSI standard parameters

$\Theta$ - hot spot temperature in degrees Celsius

$\Delta t$ - transformer operating time in hours, with hot spot temperature of $\Theta$

The above equation is built on two parameters temperature and time by which the percentage loss life is calculated. In order to get accurate estimation using this model is a challenge due to the fact that ageing is not completely dependent on thermal activity, but also due to moisture and oxygen content present in transformer oil. Other challenge is to find accurate hot spot location and its time duration because both the parameters are estimated and considered. So, by above factors this model will overestimate the residual life.

Cheim and Dupont is based on Arrhenius model but their expression will relate DP and 2FAL values. The model was formed by assuming that the ageing is an indicator of average winding insulation degradation and Cheim and Dupont equation is given below [3]

$L o L=\alpha \cdot \ln (2 F A L)+\beta$

where,

$\alpha, \beta$ - fitting parameters based on type of paper

$2 \mathrm{FAL}$ - average value, in ppm, for a transformer operating $t$ hour, having a temperature gradient of the winding being $\Delta \Theta$.

$$
D P=\left(\frac{2 F A L}{\lambda}\right)^{\frac{1}{\psi d}}
$$

where,

$\lambda$ - representing shortened above expression for $L o L$

d- parameter representing type of paper (thermally upgraded paper or normal Kraft)

This above equation is better for estimation of paper insulation as it considers both insulation paper type and hottest spot temperature gradient. Further, 2-FAL concentration is an average value of ageing rates from different hotspots in winding of field transformers so, not an accurate 
value of weakest spot. Both Arrhenius and Chiem Dupont expressions does not consider moisture and oxygen effect directly in paper ageing. Apart from this Mathematical models have been developed based on relationship between the furans (2-FAL) and DP value. Such mathematical equations are given below:

Table 7. Mathematical models representing correlation between 2-FAL and DP value

\begin{tabular}{|c|c|c|}
\hline S.no & Author & Mathematical Equation \\
\hline 1. & VAURCHEX [6] & $D P=\frac{2.6-\log _{10}(2 F A L)}{0.0049}$ \\
\hline 2. & CHENDONG [7] & $D P=\frac{1.51-\log _{10}(2 F A L)}{0.0035}$ \\
\hline 3. & HEISLERY.BANZER [8] & $D P=325 *\left(\frac{19}{13}-\log _{10}(2 F A L)\right)$ \\
\hline 4. & DEPABLO 1 [9] & $D P=\frac{1850}{2 F A L+2.3}$ \\
\hline 5. & DEPABLO 2 [10] & $D P=\frac{7100}{8.88+(2 F A L)}$ \\
\hline 6. & PAHLAVANPOUR [11] & $D P=\frac{800}{(0.186) * 2 F A L+1}$ \\
\hline 7. & STEBBINS [6] & $D P=\frac{\log (2 F A L * 0.88)-4.51}{-0.0035}$ \\
\hline 8. & BURTON [12] & $D P=\frac{2.5-\log _{10}(2 F A L)}{0.005}$ \\
\hline 9. & DONG ET AL [13] & $D P=402.47-220.87 * \log _{10}(2 F A L)$ \\
\hline 10. & LI Y SONG [14] & $D P=-121 * \ln (2 F A L)+458$ \\
\hline 11. & CHAOUHUI [15] & $D P=405.25-347.22 * \log _{10}(2 F A L)$ \\
\hline 12. & MYERS ET AL 1[16] & $\begin{array}{c}D P=-285.7 * \log _{10}(2 F A L * 0.88) \\
+1288.6\end{array}$ \\
\hline 13. & MYERS ET AL 2 [16] & $D P=-343.8 * \log _{10}(2 F A L)+1387.5$ \\
\hline
\end{tabular}

Table 8. Brief about different methods

\begin{tabular}{||l||l|l||}
\hline \hline S.No. & Mathematical model & Formation/development of models and their assumptions \\
\hline & $\begin{array}{l}\text { VAURCHEX [6] and } \\
\text { BURTON [12] }\end{array}$ & $\begin{array}{l}\text { These equations were developed based on experimental results of } \\
\text { Kraft paper by means of sealed ageing experiments under elevated } \\
\text { temperature. }\end{array}$ \\
\hline \hline & CHENDONG [7] & $\begin{array}{l}\text { This equation was developed based on the data collected from } \\
\text { transformers that have normal Kraft paper and free breathing } \\
\text { conservators. 2-FAL is expressed in ppm. }\end{array}$ \\
\hline \hline & DEPABLO 1 [9] & $\begin{array}{l}\text { As an alternative of basic models (chengdong, burton, vuarchex) } \\
\text { DePablo has given an equation to relate 2-FAL in oil with paper DP } \\
\text { based on the theory of chain scissions where 2-FAL is expressed in } \\
\text { ppm. }\end{array}$ \\
\hline
\end{tabular}




\begin{tabular}{|c|c|}
\hline DEPABLO 2 [10] & $\begin{array}{l}\text { De Pablo developed a degradation model based on a common } \\
\text { programme of research carried out by CIGRE Task Force 15.01.03. In } \\
\text { a series of experiments carried out in a number of European } \\
\text { laboratories represented by } \\
\text { CIGRE Task Force } 15.01 .03 \text {. It was determined that the overall yield } \\
\text { of the above reaction is roughly } 30 \% \text {, that means every } 3 \text { cellulose } \\
\text { chain scissions give } 1 \text { furfural molecule. It can be shown that the } \\
\text { amount of furfural } \\
\text { Dissolved in the oil is defined by this formula. }\end{array}$ \\
\hline PAHLAVANPOUR [11] & $\begin{array}{l}\text { Depablo model was modified by Pahlavanpour in order to take into } \\
\text { consideration that paper ageing is not uniform and the assumption that } \\
20 \% \text { of the inner paper layers in the winding degrade twice as fast as } \\
\text { the rest of the insulation paper and 2-FAL is in ppm. }\end{array}$ \\
\hline STEBBINS [6] & $\begin{array}{l}\text { The concentration of 2-FAL is expressed in ppb (parts per billion). } \\
\text { Stebbins proposed a modified chengdong equation to be used for } \\
\text { thermally upgraded paper }\end{array}$ \\
\hline DONG ET AL [13] & $\begin{array}{l}\text { On experimental basis it was shown that the furfural concentration } \\
\text { dissolved in oil has a fine linear relationship with the DP of paper, } \\
\text { with the aid of an oil-paper model to simulate the infield transformers. } \\
\text { Therefore, the statistical relation between furfural concentration in oil } \\
\text { and the DP of solid insulation was investigated with the scatter } \\
\text { plotting drawn between DP vs furfural content. With the linear } \\
\text { regression, this equation was derived. }\end{array}$ \\
\hline LI Y SONG [14] & $\begin{array}{l}\text { This equation was given by considering health index and by } \\
\text { considering their weights by combining qualitative analysis. This } \\
\text { method takes contents of } \mathrm{CO} \text { and } \mathrm{CO}_{2} \text { gases and they quantify with } \\
\text { piecewise linear function. The content of furfural reflects the health } \\
\text { index and through these weights and function the equation between 2- } \\
\text { FAL and DP was given. }\end{array}$ \\
\hline CHAOUHUI [15] & $\begin{array}{l}\mathrm{CO} \text { and } \mathrm{CO}_{2} \text { in } 57 \text { examples of data are normalized firstly, and then } \\
\text { they are used in logical analysis as dependent variables. The } \\
\text { regression equations shown during normal operation has established } \\
\text { the average degree of polymerization (DP) that can be estimated by } \\
\text { furfural in the given equation. }\end{array}$ \\
\hline MYERS ET AL 1 [16] & $\begin{array}{l}\text { This method is used for non-upgraded paper insulation }\left(55^{\circ} \mathrm{C}\right. \\
\text { temperature rise) and 2-FAL is considered in ppb (parts per billion) }\end{array}$ \\
\hline MYERS ET AL 2 [16] & $\begin{array}{l}\text { This method is used for thermally upgraded paper insulation }\left(55 / 65^{\circ} \mathrm{C}\right. \\
\text { temperature rise) and 2-FAL is considered in ppb (parts per billion) }\end{array}$ \\
\hline
\end{tabular}

In these models, DP value is estimated from $2 \mathrm{FAL}$ and resulting estimation of DP is superior when compared with Arrhenius and DuPont models [5]. The limitation that is common with the models (1-6) is the 2FAL concentration that can be affected by replacement or refurbishment of oil. In this case when the oil is replaced and 2-FAL concentration is distorted will give inaccurate results. Chendong and Stebbins gave models those are limited to a particular type of transformers, i.e. according to type of paper insulation. Here DP was computed by considering furan concentration only. It is better to use furans than using time duration and hot spot gradient, since it is based on ageing by-product that may be influenced by other factors. Chendong, Burton and Vuarchex were the first researchers to establish correlation between logarithmic value of 2FAL and DP. De Pablo and Pahlvanpour illustrated five different equations to correlate 2FAL 
concentration to DP. These equations were given by different laboratories and helped to establish the correlations of furan concentration to DP.

Results from Transformer Data

Now percentage remaining life of transformer is calculated by following relation, where variation in the DP values varies from $1200 \mathrm{ppm}$ to $1000 \mathrm{ppm}$ and for deteriorated paper insulation it is $200 \mathrm{ppm}$;

$$
\% \text { life }=100 * \frac{(D P-200)}{(1200-200)}
$$

From above equation, remaining life for each DP that is estimated by different methods and graphs are plotted between DP vs Remnant life for each transformer. Considering the range of 2-FAL concentration for all the six transformers, the patterns are observed for each mathematical model and average DP is calculated. Here out of all the 13 methods, only 10 methods have been applied for Kraft paper and results are displayed in table 9 and remaining are for thermally upgraded Kraft paper.

Table 9. Estimated DP from different methods for six transformers

\begin{tabular}{|c|l|c|c|c|c|c|c|}
\hline S.no & \multicolumn{1}{|c|}{$\begin{array}{c}\text { Mathematical } \\
\text { method }\end{array}$} & Tr 1 & $\operatorname{Tr} 2$ & $\operatorname{Tr} 3$ & $\operatorname{Tr} 4$ & $\operatorname{Tr} 5$ & $\operatorname{Tr} 6$ \\
\hline 1. & Vaurchex & 805 & 737 & 520 & 608 & 593 & 602 \\
\hline 2. & Chengdong & 816 & 720 & 417 & 540 & 519 & 531 \\
\hline 3. & Depablo 1 & 789 & 772 & 541 & 681 & 663 & 673 \\
\hline 4. & Depablo 2 & 796 & 791 & 710 & 764 & 758 & 761 \\
\hline 5. & Pahlavanpour & 793 & 623 & 662 & 743 & 733 & 739 \\
\hline 6. & Burton & 769 & 702 & 490 & 576 & 562 & 570 \\
\hline 7. & Dong et al & 700 & 626 & 391 & 487 & 471 & 480 \\
\hline 8. & Li. y song et al & 833 & 740 & 744 & 546 & 544 & 555 \\
\hline 9. & Chaohui et al & 873 & 756 & 388 & 538 & 512 & 527 \\
\hline 10. & Myers 1 et al & 832 & 736 & 433 & 556 & 535 & 547 \\
\hline & Average DP & 801 & 720 & 500 & 604 & 589 & 599 \\
\hline
\end{tabular}

The graphs have been plotted for the above table by considering all the methods and shown as figure 1. Next ten plots from figure 2 to figure 11 show the plot between 2-FAL and DP for each individual model considered in the paper. Figure 12 to figure 17 shows the relationship in the form of plot between remnant life and DP for six transformers taken up for investigations. Equation 1 gives the remaining life in percentage but in order to estimate transformer paper life in years equation 2 given by Pradhan et al. [17] is used and results are displayed in the following table 10

$$
\text { elapsed life }(\text { years })=20.5 * \ln \left[\frac{1100}{D P}\right]
$$

Pradhan et al. [17] the parameters considered are authors assume $\mathrm{DP}_{0}-1100$; transformer life is 35 year 
Table 10. Results of remaining life estimation in years

\begin{tabular}{|c|c|c|c|c|c|c|}
\hline Model & $\operatorname{Tr} 1$ & $\operatorname{Tr} 2$ & $\operatorname{Tr} 3$ & $\operatorname{Tr} 4$ & $\operatorname{Tr} 5$ & $\operatorname{Tr} 6$ \\
\hline Avg DP value & 801 & 720 & 500 & 604 & 589 & 599 \\
\hline \multicolumn{7}{|c|}{ Time of operation of paper insulation (in years) } \\
\hline Pradhan et al. [17] & 6.5 & 8.6 & 16.6 & 12.2 & 12.8 & 12.4 \\
\hline $\begin{array}{c}\text { Transformer life } \\
\text { time of operation } \\
\text { (in years) }\end{array}$ & 35 & 35 & 35 & 35 & 35 & 35 \\
\hline $\begin{array}{c}\text { Remaining life } \\
\text { time (in years) }\end{array}$ & 28.5 & 26.4 & 18.4 & 22.8 & 22.2 & 22.6 \\
\hline
\end{tabular}

According to Pradhan et al. [17] the time of operation of paper insulation is calculated by substituting the estimated DP in equation 2. Now the transformer DP below 200 is considered as end of life and by the equation the estimated time of operation of transformer insulation is 35 years. By subtracting the estimated time of operation from transformer life time operation the remaining lifetime of insulation in years are obtained.

\section{DP VS 2-FAL}

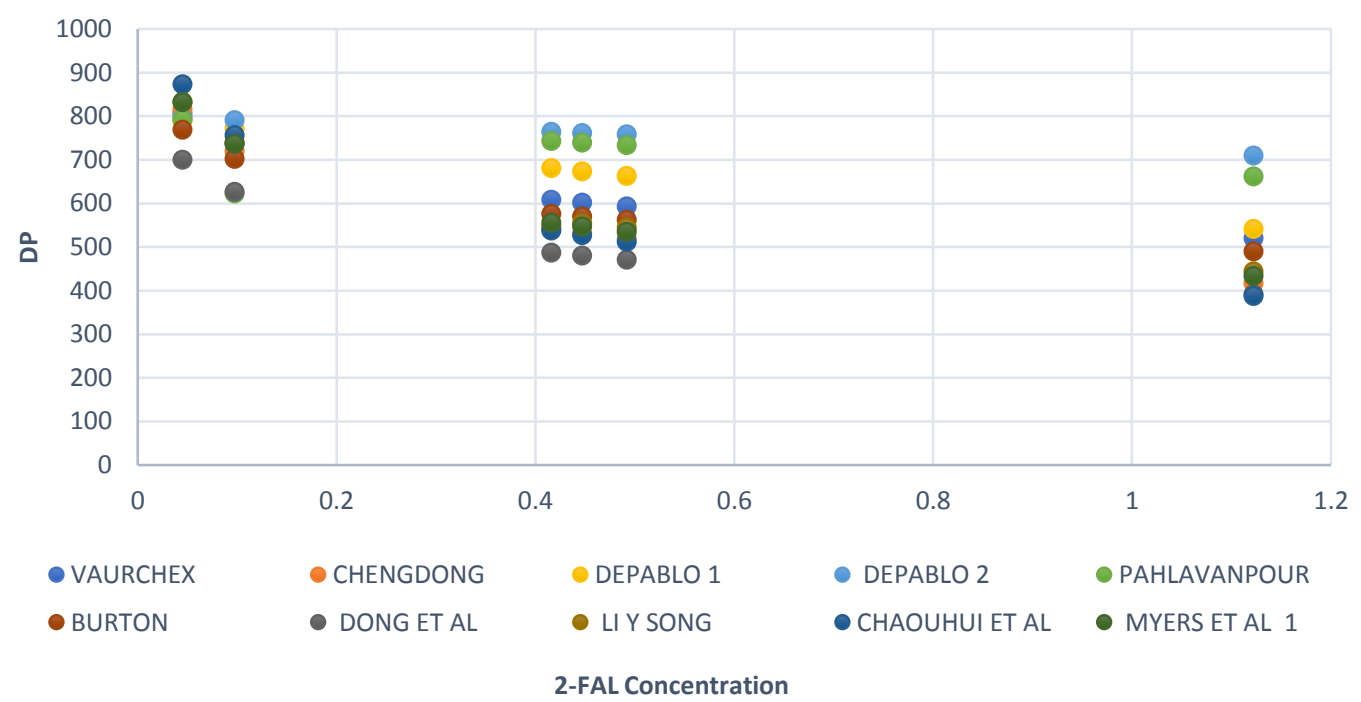

Figure 1. DP vs 2-FAL concentration for above mentioned methods 
Deepak Kanumuri, et al.

Graphs plotted for each method:

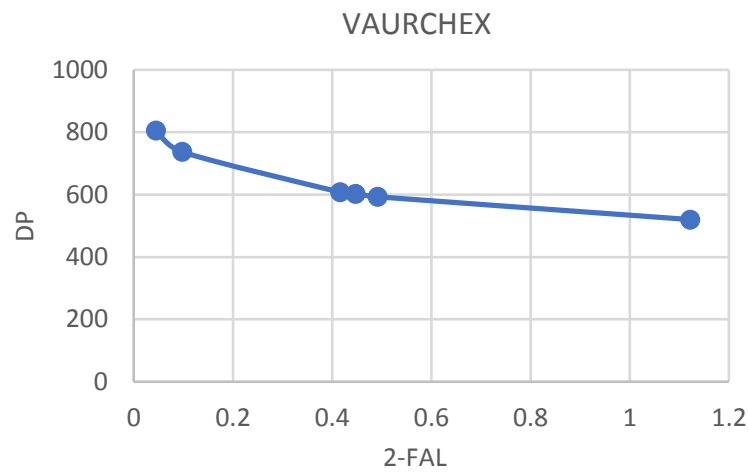

Figure 2. DP vs 2-FAL (vaurchex)

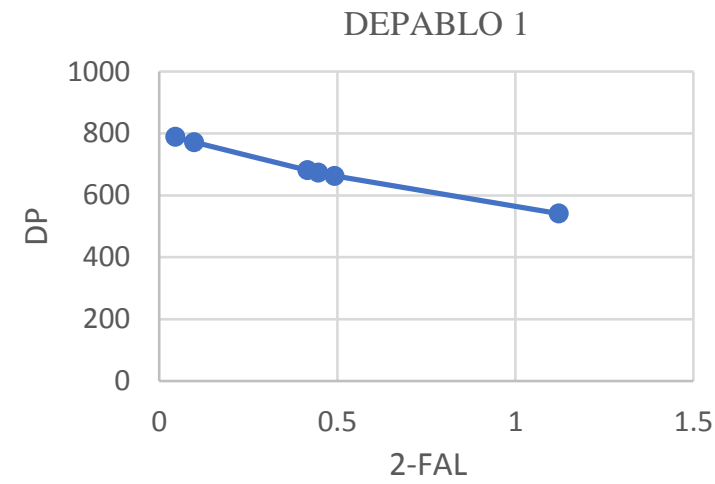

Figure 3. DP vs 2-FAL (chengdong)

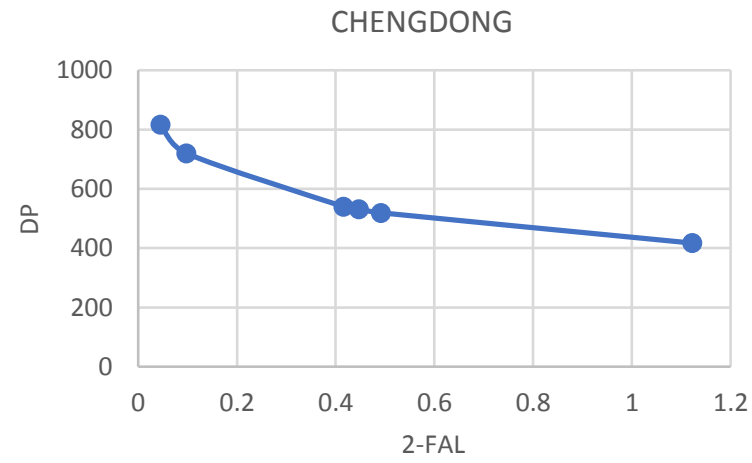

Figure 4. DP vs 2-FAL (Depablo 1) 


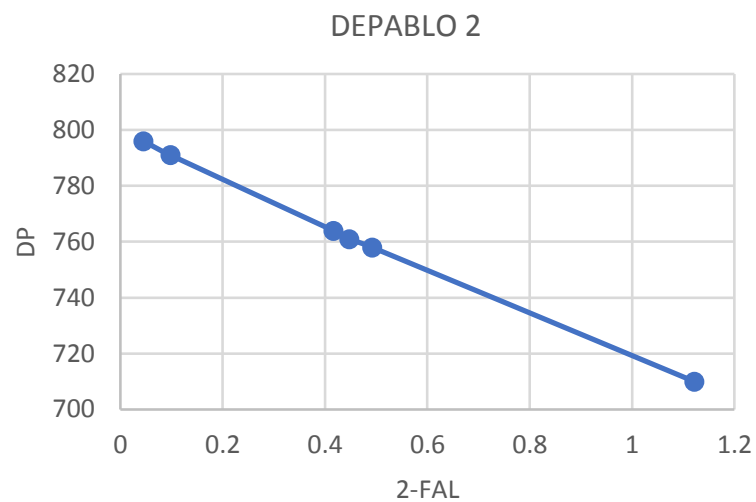

Figure 5. DP vs 2-FAL (Depablo 2)

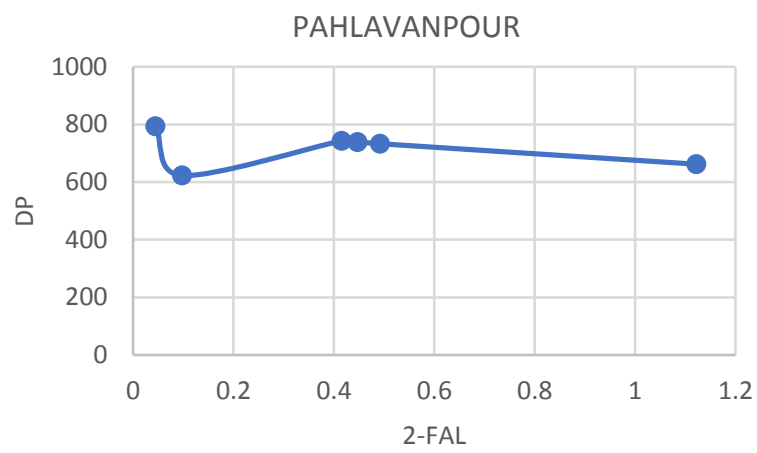

Figure 6. DP vs 2-FAL (pahlavanpour)

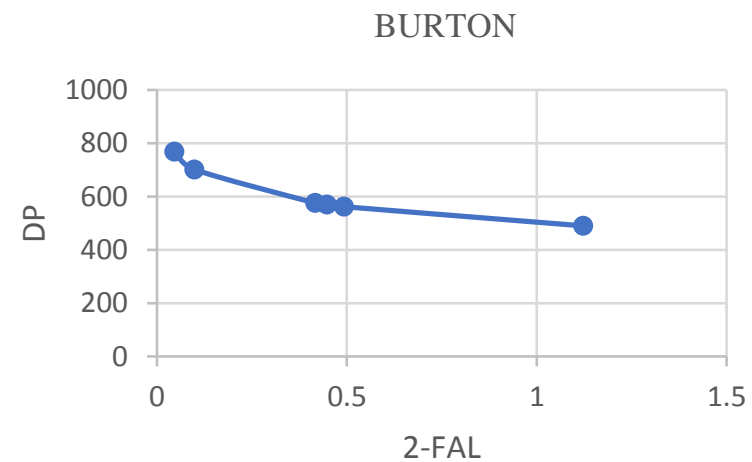

Figure 7. DP vs 2-FAL (Burton) 
Deepak Kanumuri, et al.

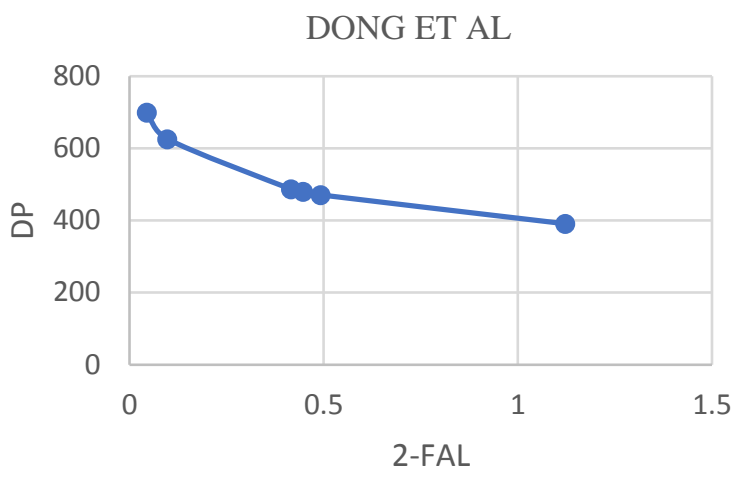

Figure 8. DP vs 2-FAL (Dong et al)

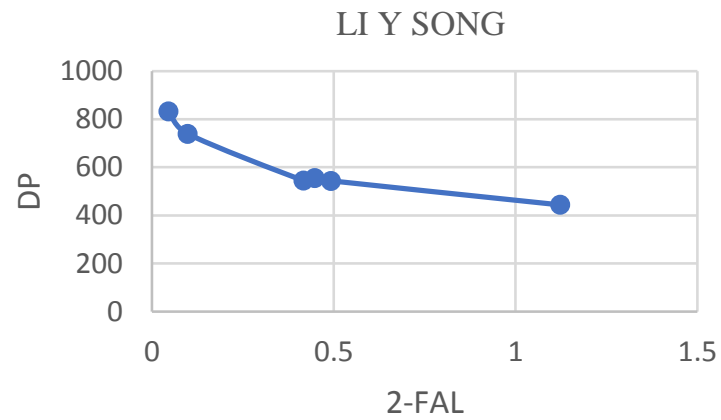

Figure 9. DP vs 2-FAL (Li. y song)

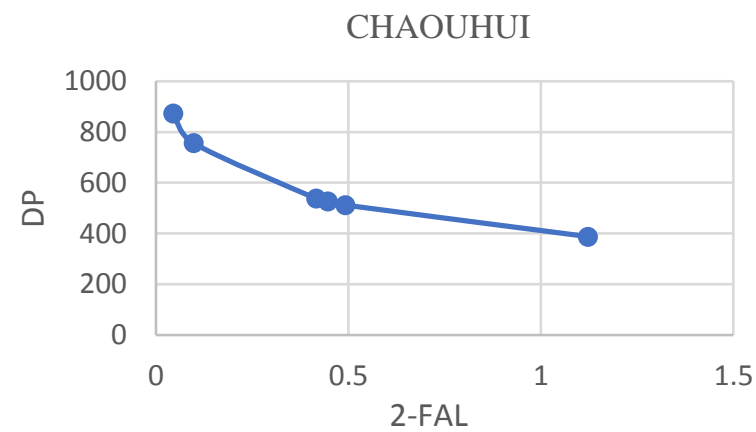

Figure 10. DP vs 2-FAL (chaouhui) 
Analysis Using Various Approaches for Residual Life Estimation

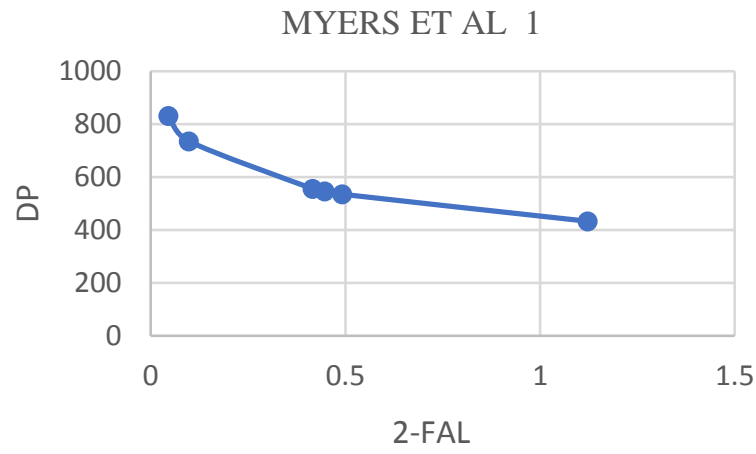

Figure 11. DP vs 2-FAL (Myers et al 1)

Graphs plotted for each transformer estimated DP vs Remnant life:

DP VS Remnant life

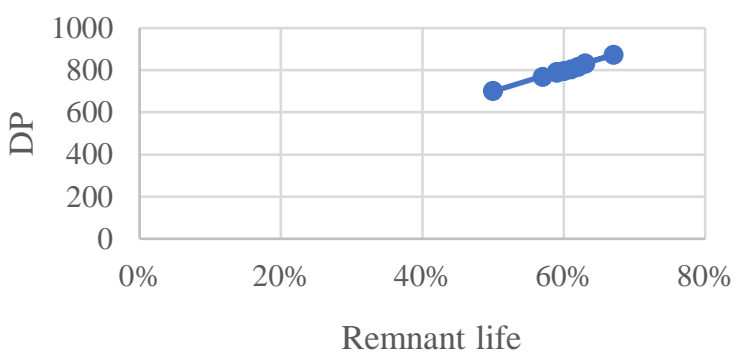

Figure 12. Transformer 1

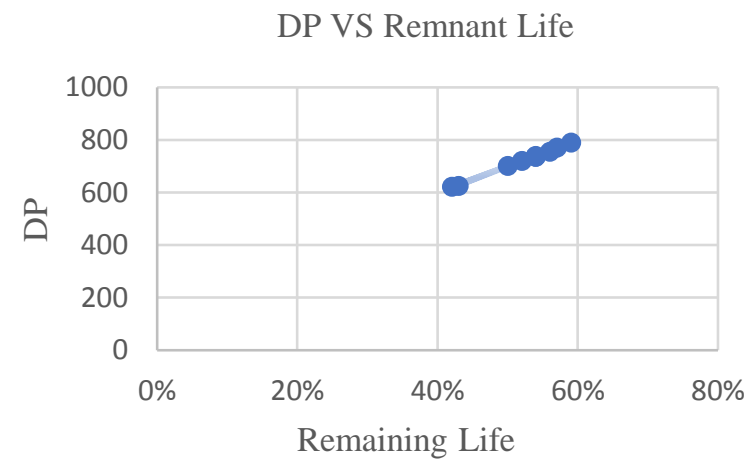

Figure 13. Transformer 2 
Deepak Kanumuri, et al.

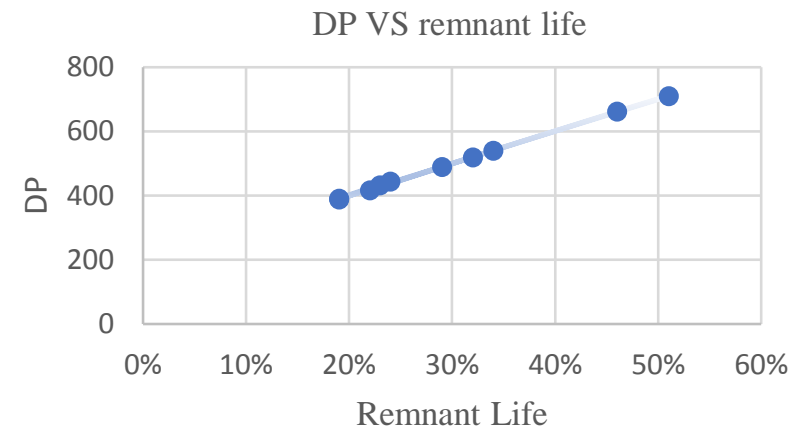

Figure 14. Transformer 3

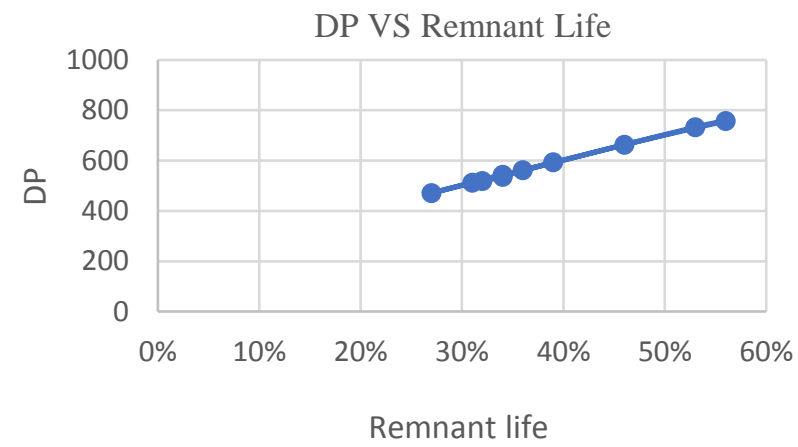

Figure 15. Transformer 4

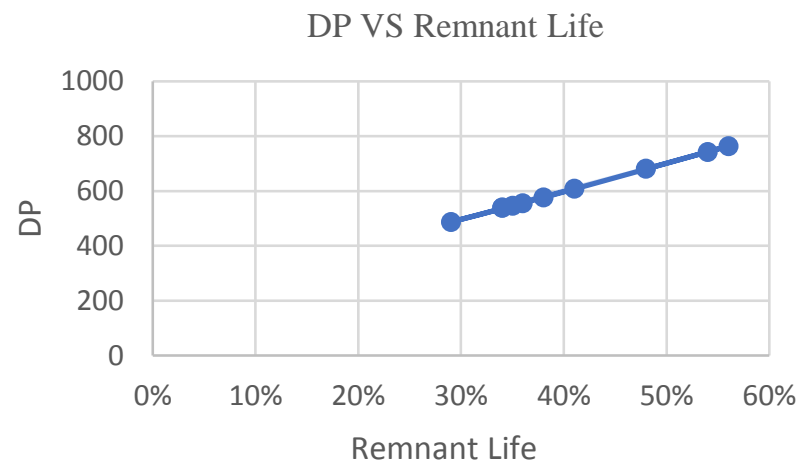

Figure16. Transformer 5 


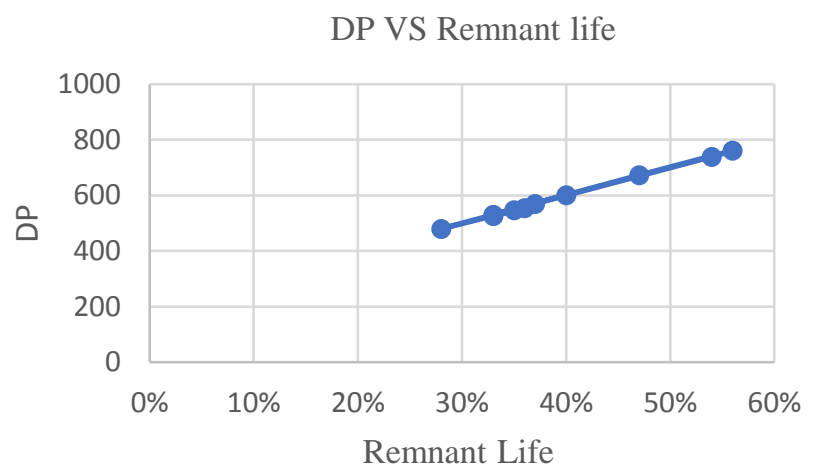

Figure 17. Transformer 6

\section{Results and discussions}

Many researchers have attempted statistical analysis on furan content data for oil samples taken from field transformers. The main purpose is to determine the threshold values of furan content for diagnostic purposes. These results might have a very limited application to field transformers those are using TUK paper or Kraft paper designed as per IEEE standards [18]. In present work, the results have been obtained for different transformers by using various mathematical models and it has been observed that the DP value of all the methods with respect to remnant life follows a definite pattern, even though they all uses different assumptions for their models for all the six transformers hence it can be observed that

a) For transformer 1, the concentration of $2-\mathrm{FAL}$ value is $0.045 \mathrm{ppm}$ and its average DP calculated from all methods is 801 , and remaining percentage of life by equation (1) is $60 \%$. The transformer is above 40 years but the value of furan is less i.e. $0.045 \mathrm{ppm}$ because oil refurbishment has been done in 2008. So, the estimated value for this transformer might be inaccurate. Range of percentage remnant life is about 50\%-67\%, calculated for different methods of estimated DP.

b) For transformer 2, the concentration of 2-FAL value is $0.0976 \mathrm{ppm}$ and its average DP calculated from all methods is 720 , and remaining percentage of life by equation (1) is $52 \%$. Range of percentage remnant life is about $42 \%-59 \%$ calculated for different methods of estimated DP.

c) For transformer 3, the concentration of 2-FAL value is $1.122 \mathrm{ppm}$ and its average DP calculated from all methods is 500, and remaining percentage of life by equation (1) is $30 \%$. Range of percentage remnant life is about $19 \%-34 \%$ calculated for different methods of estimated DP. But depablo 2 and pahlavanpour models show $51 \%$ and $46 \%$ due to different factors or assumptions considered by these methods.

d) For transformer 4, in which the concentration of $2-\mathrm{FAL}$ value is $0.416 \mathrm{ppm}$ and its average DP calculated from all methods is 604 , and remaining percentage of life by equation (1) is $40 \%$. Range of percentage remnant life is about $29 \%-48 \%$ calculated for different methods of estimated DP.

e) For transformer 5, in which the concentration of 2-FAL value is $0.492 \mathrm{ppm}$ and its average DP calculated from all methods is 589, and remaining percentage of life by equation (1) is $39 \%$. Range of percentage remnant life is about 27\%-39\% calculated for different methods of estimated DP. Except for depablo equations, pahlavanpour equations.

f) For transformer 6 , in which the concentration of $2-F A L$ value is $0.447 \mathrm{ppm}$ and its average DP calculated from all methods is 599 , and remaining percentage of life by equation (1) is $40 \%$. Range of percentage remnant life is about $28 \%-40 \%$ calculated for different methods of estimated DP. Except for depablo equations, pahlavanpour equations. 
From above analysis it can be observed that using different mathematical equations, and the 2-FAL concentration that estimates the DP is close to original in the early stages of insulation paper ageing, but there is scattering trends that are greater at low DP levels for paper insulation because of different ageing conditions due to different factors.

The remaining life of insulation in years from table 10 shows that for transformer 1- 28.5 years of operation time is left and similarly for transformer 2- 26.4 years; for transformer 3- 18.4 years; for transformer 4- 22.8 years; for transformer 5- 22.2 years; for transformer 6- 22.6 years of operation time is remaining.

Depablo and pahlavanpour equations show over estimation of DP values due to their assumptions considered. And from graphical representation shown above, i.e. Figures (2-11) between DP vs 2-FAL concentration there are some points to be observed. The graphs that have similar graphical representation (figures $2,3,7,8$ ) are vaurchex, chengdong, burton, Dong et al models. Another set of graphs (figures 10,11) that are similar are Chaouhui and Myer's et al. The application of mathematical equations has revealed that methods given by Vaurchex and Myers et al. for non-upgraded or normal Kraft paper gives the most reliable results when studied transformers has less than 8 years' service [19]. But, when the older transformers are considered, estimation of remnant lifetime based on furanic compounds concentration is quite unpredictable. In this consideration, when transformers are older (i.e. around 30 years) proposed mathematical models by Dong et al. and Li y Song. gives more similar data related to real data.

The Chendong [7] model is used to calculate DP for all types of transformers, regardless of the type of paper insulation used in them. So, transformers with various types of paper insulations will show different amounts of furanic compounds depending on different ageing conditions. These results will be based on type of paper used. As an example, results of the model used for sealed conservator and nitrogen blanketed transformers could underestimate the DP value in transformers that has TUK. Under such conditions, the result obtained could provide false sense of security. Chengdong model is best for estimation of average DP value in transformers having Kraft paper as insulation and for free-breathing conservators. For other paper insulation systems this equation could be used for estimating paper degradation by thermal events.

Several mathematical models used for the estimation of remnant lifetime of transformers have determined that these models are not fit to estimate the condition accurately. Hence, it is vital to study the tendency of dielectric and physicochemical properties of dielectric oil when the transformer is in-service. The transformer condition cannot be obtained by only considering recent sample measures of oil properties. As the dielectric oil and insulating paper age, variables that are measured and degradation products will not be in continuous pattern and will fluctuate over time. This indirect methods has many uncertainties which are to be researched are 2-FAL stability which is present in oil by the terms of temperature and time, the period it takes to find 2-FAL concentration after the oil is processed gives the ageing process, up to what level the in accuracy of indirect methods can be allowed and why, integrity of 2-FAL stability takes into consideration the recent discoveries and new models should be proposed by considering more number of factors which are highly accurate and are reliable in remaining life calculation more accurately.

\section{Conclusions}

In this paper, various indirect methods are studied, compared and different conclusions are drawn based on the results obtained from the mathematical models which show correlation between the furan concentration(2-FAL) and DP of the six different field transformers. It has been observed that the DP values of single transformer calculated from same concentration of 2FAL has a range of values depending on their assumptions and considerations followed by different models. Further, in this study the formation or development of different equations on various laboratory results and assumptions considered for each model are discussed briefly. The graphs have been plotted between 2-FAL and DP for each individual method taken in this paper and graphs between DP's and their remnant life assessed through them are investigated. Average values of DP 
taken from all the results of the mathematical models and remnant life of a particular transformer is assessed. From the data of transformers, the range of remnant life and the values obtained for different models is known.

\section{References}

[1]. "IEEE Guide for Loading Mineral-Oil-Immersed Transformers", IEEE Std. C57.91-1995.

[2]. Inderpreet Kaur, Preetinder Singh, Residual life assessment with DGA, furan content in transformer oil and degree of polymerization of solid insulation. International journal of scientific and research publications, Vol. 6, issue 7, July 2016, ISSN 2250-3153.

[3]. Lewand LR. Practical Experience Gained from Furanic Compound Analysis. Doble Engineering Company. 2006 - 73rd Annual International Doble Client Conference.

[4]. J. Haema and R. Phadungthin, "Development of condition evaluation for power transformer maintenance", in 4th Int. Conf. on Power Eng. Energy and Elect. Drives, (2013), pp. 620623.

[5]. Cheim L Dr., Dupont C, On the Correlation Between 2-Furfural and DP A New Transformer Ageing Model. Doble Engineering Company, 2004.

[6]. R. D. Stebbins, D. S. Myers and A. B. Shkolnik, "Furanic compounds in dielectric liquid samples: Review and update of diagnostic interpretation and estimation of insulation ageing", in 7th Int. Conf. on Properties and Appl. of Dielectr. Mater., (2003), pp. 921-926.

[7]. X. Chendong, "Monitoring paper insulation ageing by measuring furfural contents in oil", in 7th Int. Symp. on High Voltage Eng., (1991), pp. 26-30.

[8]. A. Heisler and A. Banzer, "Zustandsbeurteilung von transformatoren mit furfurolbestimmung", Das Magazin für die Energiewirtschaft, (2003), pp. 58-59.

[9]. A. De Pablo, "Interpretation of furanic compounds analysis degradation models", CIGRE, (1997).

[10]. A. De Pablo, "Furfural and ageing: How are they related", IEEE Colloquium on Insulating Liquids, (1999), pp. 5/1-5/4.

[11]. Pahlavanpour B (Prof.), Eklund M (Dr.), Thermal Ageing of Mineral Insulating Oil and Krafts Paper, Nynas Naphthenics AB, SE-14982 Nynashamn, Sweden

[12]. L. Cheim, D. Platts, T. Prevost, and S. Xu, "Furan analysis for liquid power transformers," Electrical Insulation Magazine, IEEE, vol. 28, pp.8-21, 2012.

[13]. M. Dong, Z. Yan, and G. J. Zhang, "Comprehensive diagnostic and aging assessment method of solid insulation in transformer", in Conf. on Electr. Insul. and Dielect. Phenomena. Annual Report, (2003) pp. 137-140.

[14]. E. Li and B. Song, "Transformer Health Status Evaluation Model Based on Multi-feature Factors", in Int. Conf. on Power Syst. Technol., (2014), pp. 1417-1422.

[15]. L. Chaohui, Z. Bide and Y. Yuchun, "The aging diagnosis of solid insulation for oilimmersed power transformers and its remaining life prediction", in Asia-Pacific Power and Energy Eng. Conf., (2010), pp. 1-3.

[16]. A. B. Shkolnik, R. T. Rasor and S. D. Myers, "Statistical insights into furan interpretation using a large dielectric fluid testing database", in IEEE PES Transmission and Distribution Conf. and Expo., (2012), pp. 1-8

[17]. M. K. Pradhan, T.S. Ramu, "On the estimation of elapsed life of oil-immersed power transformers", IEEE Trans. Power Del., (2005), Vol. 20(3), pp. 1962-1969.

[18]. TK, Review of Modern Diagnostic Techniques for Assessing Insulation Condition in Aged Transformers. IEEE Transaction on Dielectrics and Electrical insulation, Vol. 10, No. 5; October 2003

[19]. F. Ortiz, C. Fernandez et al, Estimating the age of power transformers using the concentration of furans in dielectric oil. Renewable energy and power quality, journal (RE\&PQJ), ISSN 2172-038 X, No.14 May 2016.

[20]. Griffin PI, Assessment of Paper and Other Cellulosic Materials in Service-Aged Transformers. Doble Engineering Company, Presentation at Southeastern Electric Exchange, June 24, 1999. 
[21]. R. Liao, C. Guo, K. Wang, L. Yang, S. Grzybowski and H. Sun, "Investigation on thermal aging characteristics of vegetable oil-paper Insulation with flowing dry air", IEEE Trans. Dielectr.Elect. Insul, (2013), Vol. 20(5), pp. 1649-1658.

[22]. A. J. Kachler and I. Höhlein, "Aging of cellulose at transformer service temperatures. Part 1: Influence of type of oil and air on the degree of polymerization of pressboard, dissolved gases and furanic compounds in oil", IEEE Electr. Insul. Mag., (2005), Vol. 21(2), pp. 1521.

[23]. A. J. Kachler and I. Höhlein, "Aging of cellulose at transformer service temperatures. Part 2: Influence of moisture and temperature on degree of polymerization and formation of furanic compounds in free-breathing systems", IEEE Electr. Insul. Mag., (2005), Vol. 21(5), pp. 20-24.

[24]. H. Lütke, I. Höhleim and A. J. Kachler, "Transformer aging research on furanic compounds dissolved in insulating oil", CIGRE (2002).

[25]. Yuan Li, Ming-Jie Tang, et.al "Aging Assessment of Power Transformer Using Multiparameters", International Journal on Electrical Engineering and Informatics - Vol 5, Number 1, March 2013.

[26]. Chilaka Ranga and Ashwani Kumar Chandel, "Expert System for Health Index Assessment of Power Transformers", International Journal on Electrical Engineering and Informatics - Vol 9, Number 4, December 2017.

[27]. Karunika Diwyacitta, Rahman Azis Prasojo, "Study on Correlation Among Oil Dielectric Characteristics, Dissolved Gases, and Operating Life of $150 \mathrm{kV}$ Power Transformer" International Journal on Electrical Engineering and Informatics - Vol 9, Number 3, September 2017.

[28]. Rahman Azis Prasojo and Suwarno, "Power Transformer Paper Insulation Assessment based on Oil Measurement Data using SVM-Classifier" International Journal on Electrical Engineering and Informatics - Vol 10, Number 4, December 2018.

[29]. Fari Pratomosiwi, Norasage Pattanadech et.al, "Considerations for Dielectric Properties Measurements of Oil Immersed Pressboard", International Journal on Electrical Engineering and Informatics - Vol 4, Number 3, October 2012

[30]. D. Martin and T. Saha, "A review of the techniques used by utilities to measure the water content of transformer insulation paper," in IEEE Electrical Insulation Magazine, vol. 33, no. 3, pp. 8-16, May-June 2017.

[31]. J. Zhang, F. Wang, J. Li, X. Li and Q. Zhou, "Ageing characterization of oil impregnated paper insulation based on dispersion staining colors," in IEEE Transactions on Dielectrics and Electrical Insulation, vol. 25, no. 5, pp. 1587-1597, Oct. 2018.

[32]. G. Dombek and Z. Nadolny, "Influence of paper type and liquid insulation on heat transfer in transformers," in IEEE Transactions on Dielectrics and Electrical Insulation, vol. 25, no. 5, pp. 1863-1870, Oct. 2018.

[33]. J. Li, J. Zhang, F. Wang, Z. Huang and Q. Zhou, "A novel aging indicator of transformer paper insulation based on dispersion staining colors of cellulose fibers in oil," in IEEE Electrical Insulation Magazine, vol. 34, no. 4, pp. 8-16, July-August 2018.

[34]. D. Feng, L. Yang, R. Liao, L. Zhou and Y. Lin, "Effect of moisture content on the production and partitioning of furfural in oil-paper insulation," in IEEE Transactions on Dielectrics and Electrical Insulation, vol. 25, no. 6, pp. 2389-2397, Dec. 2018.

[35]. A. Teymouri and B. Vahidi, "CO2/CO concentration ratio: A complementary method for determining the degree of polymerization of power transformer paper insulation," in IEEE Electrical Insulation Magazine, vol. 33, no. 1, pp. 24-30, January-February 2017.

[36]. U. M. Rao, H. Pulluri and N. G. Kumar, "Performance analysis of transformer oil/paper insulation with ester and mixed dielectric fluids," in IEEE Transactions on Dielectrics and Electrical Insulation, vol. 25, no. 5, pp. 1853-1862, Oct. 2018. 


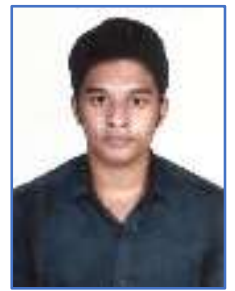

Deepak Kanumuri is pursuing $\mathrm{PhD}$ in Electrical engineering branch at IIT Guwahati and received MTech degree in the branch of 'Condition monitoring control and protection of electrical apparatus' at NIT Hamirpur, Hamirpur (H.P.), India in 2019. He has received his B. Tech degree in Electrical and electronics engineering from ANITS, Visakhapatnam in the year 2016 (A.P.), India. His research interests include High voltage engineering, Dielectrics and condition monitoring of electrical equipment.

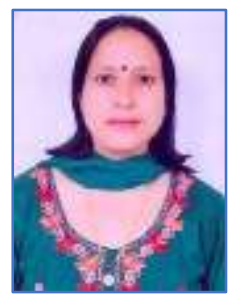

Veena Sharma, Head of The Department (Associate Professor), EED, NIT Hamirpur. Veena Sharma received her B. Tech degree in Electrical Engineering from REC Hamirpur, Himachal Pradesh, India, in 1990, and MTech degree in Instrumentation and Control Engineering from Punjab Agricultural University Ludhiana, India, in 1993 and $\mathrm{PhD}$ from Punjab Technical University, Jalandhar, in 2006. She is currently working as an Associate Professor in EED, National Institute of Technology, Hamirpur, Himachal Pradesh, India. She has published a number of research papers in national and international journals. She has been providing consultancy services to electric power industry. Her research interests include power system optimization, power generation, operation, and control.

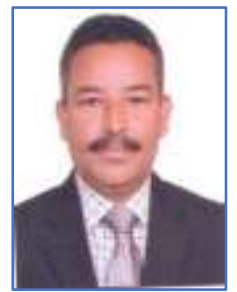

O. P. Rahi, Associate Professor, NIT Hamirpur. He received his three years Diploma in Electrical Engineering from Govt. Polytechnic, Sunder Nagar, B.Tech. Degree from REC Hamirpur, ME from PEC, Chandigarh, and Ph.D. from NIT, Hamirpur, HP, India. Dr. Rahi taught in Electrical Engineering Department of Govt. Polytechnic Sunder Nagar as Demonstrator and later on as Lecturer. In 2000, he joined NIT Hamirpur currently he is an Associate Professor in NIT Hamirpur. Dr. Rahi is Member IEEE (USA), Fellow (IEI), LMISTE, LMISOI, SMIACSIT etc. He has published more than 50 research papers in International Journals and Conferences. His research interests include Power System, Hydro Power, and Renewable Energy. Presently, he is on expert panel for various Public Service Commissions and Service Selection Boards of Northern India. 